\title{
Comentario
}

\section{Las necesidades de información de la comunidad como elemento central del desarrollo de la biblioteca pública}

$\coprod_{\text {as bibliotecas públicas son las instituciones sociales que }}$ las rodean.

Las comunidades, al estar integradas por personas, presentan de entrada una variedad de personalidades, ocupaciones, intereses, nivel social, etcétera. Asimismo sus necesidades y comportamiento informativo son diversos, pero es precisamente ahí donde la labor de la biblioteca pública está inmersa.

Por lo anterior, las bibliotecas públicas deben atender una variedad amplia de personas: niños, adolescentes, adultos, personas de la tercera edad, profesionistas, comerciantes, empleados, obreros, entre otros. Porque la biblioteca pública está rodeada de entidades o instituciones como son escuelas preescolares, primarias, secundarias y preparatorias, universidades, escuelas comerciales y de otra índole, así como de fábricas, oficinas o despachos de profesionistas en su labor particular: médicos, abogados, dentistas, etcétera, y también de pequeños comercios como son misceláneas, tiendas de abarrotes, papelerías, boneterías, etcétera.

Entonces, una de las partes medulares de la biblioteca pública son las comunidades que las rodean y las personas que acuden a ella y que, además, presentan necesidades de información específicas que hay que satisfacer en su diversidad, por lo que compete a la biblioteca pública realizar esta labor.

Lo cierto es que el ser humano entre todas sus necesidades tiene las de información, porque es un organismo viviente que posee un intelecto y genera conocimiento sobre el mundo que lo rodea; busca explicaciones sobre cómo y porqué ocurren los hechos o fenómenos y sobre su propia existencia. 
De esta forma, las necesidades de información son para muchas comunidades o sectores sociales prioritarias, mientras que para otros lo son pero en distintos niveles, puesto que las necesidades primarias o fisiológicas son determinantes en su comportamiento.

La investigación sobre las necesidades de información de una comunidad permitirá determinar las variables externas e internas que afectan su surgimiento, así como el comportamiento informativo que presentan las personas para que las unidades de información o, en su caso, las bibliotecas públicas, puedan satisfacer de forma adecuada y expedita las mismas.

Las bibliotecas públicas, por su propia naturaleza, se encuentran ubicadas en diferentes regiones geográficas, insertas en diferentes comunidades. Así, para dar cuenta de su diversidad, mencionaremos algunos ejemplos en México:

- La biblioteca pública "Nezahualcóyotl" ubicada en la delegación Xochimilco, al sur de la Ciudad de México.

- La biblioteca pública ubicada en el Parque España en la Ciudad de México.

- La biblioteca pública ubicada en la ciudad de Dolores Hidalgo, Guanajuato.

- La biblioteca pública ubicada en la ciudad de San José del Cabo en Baja California Sur.

Como puede observarse, cada una de las comunidades que rodea a estas bibliotecas públicas es completamente diferente, por ende, sus necesidades de información y comportamiento informativo mantienen algunas semejanzas pero en general tienen diferencias.

Se hace, por lo tanto, conveniente un estudio de necesidades de información que ofrezca como resultado elementos que puedan ser utilizados para el desarrollo de colecciones documentales acordes con cada comunidad, servicios bibliotecarios y de información adecuados para satisfacer sus necesidades de información; así como de edificios o locales con espacio suficiente para atender a todas las personas de la comunidad que usen la biblioteca pública.

Lo anterior permitirá el desarrollo de una biblioteca local acorde con las características de su comunidad; es decir, cada 
biblioteca pública contará con sus propias colecciones documentales que respondan a las necesidades propias de la comunidad, ya que, en general, no se pueden estandarizar colecciones documentales.

Aunque las diferencias entre las distintas comunidades son obvias, existen cosas en común, puesto que pertenecemos a un mismo país. Como las necesidades de información son diferentes, sólo los estudios relativos a las mismas pueden dar las pautas para que cada biblioteca tenga un desarrollo armónico y acorde con la comunidad a la que le toca atender. Es imposible que se siga un solo modelo de biblioteca pública (idénticas colecciones documentales o acervos, servicios y espacios físicos) y funcione igual para todas las comunidades donde existe una gran diversidad de sujetos.

Ahora bien, la forma de hacer accesible la información y de organizarla, así como las guías para diseñar los servicios son propias de la organización y administración de bibliotecas, pero no son inflexibles y una adecuada administración es la que se adapta a las instituciones en las que se tome en cuenta a las comunidades y al contexto que las rodea.

Por lo anterior, para alcanzar su desarrollo, las bibliotecas públicas deben adentrarse en la comunidad en la que están brindando sus servicios y acervos, y sólo lo pueden lograr investigándola, estudiando su entorno, desentrañando sus necesidades de información y, a partir de su análisis, iniciar un proceso de desarrollo de colecciones documentales, el diseño de servicios bibliotecarios y de información con la ayuda de la tecnología cuando así se requiera y de la formación profesional, capacitación y adiestramiento del personal que labora en dichas bibliotecas, sin descuidar el diseño de los espacios, locales o edificios.

Juan José Calva González 